Abstracted/indexed in Academic Search Complete, Agroforestry Abstracts, Asia Journals Online, Bangladesh Journals Online, Biological Abstracts, BIOSIS Previews, CAB Abstracts, Current Abstracts, Directory of Open Access Journals, EMBASE/Excerpta Medica, Google Scholar, HINARI (WHO), International Pharmaceutical Abstracts, Open J-gate, Science Citation Index Expanded, SCOPUS and Social Sciences Citation Index; ISSN: 1991-0088

\title{
Nigella sativa improves the carbon tetrachloride-induced lung damage in rats through repression of erk/akt pathway
}

\author{
Abdullah Aslan' ${ }^{\text {, Didem Boydak }}{ }^{\text {, Muhammed Ismail Can }}{ }^{2}$ and Tuncay Kuloglu³ \\ ${ }^{1}$ Department of Biology, Faculty of Science, Firat University, Elazig, Turkey; ${ }^{2}$ Department of \\ Biotechnology and Molecular Biology, Aksaray University, Aksaray, Turkey; ${ }^{3}$ Department of \\ Histology and Embryology, Faculty of Medicine, Firat University, Elazig, Turkey.
}

\begin{tabular}{|c|c|}
\hline \multicolumn{2}{|l|}{ Article Info } \\
\hline $\begin{array}{l}\text { Received: } \\
\text { Accepted: } \\
\text { Available Online: }\end{array}$ & $\begin{array}{l}26 \text { May } 2015 \\
\text { 24 June } 2015 \\
\text { 24 July } 2015\end{array}$ \\
\hline \multicolumn{2}{|c|}{ DOI: 10.3329/bjp.v10i3.23486 } \\
\hline \multicolumn{2}{|c|}{$\begin{array}{l}\text { Cite this article: } \\
\text { Aslan A, Boydak D, Can MI, Kuloglu } \\
\text { T. Nigella sativa improves the carbon } \\
\text { tetrachloride-induced lung damage in } \\
\text { rats through repression of erk/akt } \\
\text { pathway. Bangladesh J Pharmacol. } \\
\text { 2015; 10:000-00. }\end{array}$} \\
\hline
\end{tabular}

\begin{abstract}
The objective of this study was to examine whether Nigella sativa plays a protective role against the damage in the lung by administering carbon tetrachloride $\left(\mathrm{CCl}_{4}\right)$ to rats. Male Wistar albino $(\mathrm{n}=28,8$ weeks old $)$ rats were divided into 4 groups: a) negative control: Normal water consuming group to which no $\mathrm{CCl}_{4}$ and N. sativa was administered; b) Positive control: Normal water consuming group to which no $\mathrm{CCl}_{4}$ was administered but $N$. sativa was administered; c) $\mathrm{CCl}_{4}$ Group: Normal water consuming and group to which $\mathrm{CCl}_{4}$ was administered $\left(1.5 \mathrm{~mL} / \mathrm{kg}\right.$, ip); d) N. sativa plus $\mathrm{CCl}_{4}$ group: $\mathrm{CCl}_{4}$ and $N$. sativa administered group $(1.5 \mathrm{~mL} / \mathrm{kg}$, ip). Caspase-3, caspase -9, erk, akt protein syntheses were examined via Western blotting. Malondialdehyde determination in lung tissue was made using spectrophotometer. As a results, malondialdehyde amount was decreased in the $\mathrm{CCl}_{4}$ plus $N$. sativa group in comparison to $\mathrm{CCl}_{4}$ group whereas caspase-3, caspase-9 was increased and erk, akt had decreased. These results show that $N$. sativa protects the lung against oxidative damage.
\end{abstract}

\section{Introduction}

Many clinical studies carried out today on experimental animals put forth the toxic effects of free radicals on the cells as well as the therapeutic effects of antioxidant systems on these toxic effects (Li et al., 2011; Aslan et al., 2014; Aslan, 2015). Carbon tetrachloride $\left(\mathrm{CCl}_{4}\right)$ is one of the chemicals that can cause severe toxic effects on the body and is frequently used to create experimental damage (Vuda et al., 2012). It can easily enter the body via respiration, ingestion or dermal absorption and is rapidly absorbed via the gastrointestinal channel. A significant portion of $\mathrm{CCl}_{4}$ in humans settles on the fat tissue. It then continues to move towards the lungs. About $4 \%$ of the metabolized $\mathrm{CCl}_{4}$ is thrown out via respiration and the remainder interacts with the protein and intracellular molecules (Al-Dbass et al., 2012; Aslan and Can, 2014).
Some plants known as medicinal plants have been widely used in the treatment of many diseases since ancient times. Nigella sativa is one of these plants and it has been used for medicinal purposes for centuries with protective effects especially on the lungs which have been put forth in light of recent experimental studies (Sahin et al., 2003). Caspase-3, caspase-9, erk and akt proteins are important for the apoptosis mechanism (Korsmeyer, 1999; Aslan and Can, 2014; Lu and Xu, 2006). In this study, rats were administered with carbon tetrachloride and it was examined whether $N$. sativa plays a protective role against damages in the lungs or not.

\section{Materials and Methods}

\section{Chemical substances and N. sativa}

The primary antibodies used in the Western blotting 
stage were obtained from BioVision (USA) whereas secondary antibody was obtained from Santa Cruz Biotechnology (USA). All other chemicals used in experimental work were acquired from Sigma-Aldrich (Germany), Bio-Rad (USA), Bio Shop (Canada) and Merck (USA). Dust form NS seeds to be boiled and mixed in the daily drinking waters of rats were acquired from oz gida organik and yoresel urunler Ltd. Sti. (Elazı $\breve{g})$.

\section{Animal material and research groups}

All of the animal experimentation work of our study was carried out at the Firat University Experimental Animals Research Institute (FUDAM) with consent number 129 of Firat University Animal Experiments Ethics Council during the meeting on 27/11/2013. 28 male Wistar albino $(n=28,8$ weeks) rats were used in the study. Light and dark periods of 12 hours were applied to rats. The rats were distributed into 4 groups according to their live weights. The groups were: (i) Negative control: Normal water consuming group to which no $\mathrm{CCl}_{4}$ and $N$. sativa was administered; b) Positive control: Normal water consuming group to which no $\mathrm{CCl}_{4}$ is administered but $N$. sativa was administered; c) $\mathrm{CCl}_{4}$ Group: Normal water consuming group to which $\mathrm{CCl}_{4}$ was administered $(1.5 \mathrm{~mL} / \mathrm{kg}$ live weight, i.p); d) $\mathrm{CCl}_{4}+N$. sativa group: $\mathrm{CCl}_{4}$ and $N$. sativa administered group (1.5 mL/ $\mathrm{kg}$ live weight, i.p). The extract of boiled $N$. sativa seeds was mixed into the drinking water of animals to be used as $N$. sativa source $(10 \% \mathrm{w} / \mathrm{v})$. The initial live weights of the animals were arranged to be equal. Live weights were recorded 3 times weekly throughout the study.

\section{$\mathrm{CCl}_{4}$ application}

$\mathrm{CCl}_{4}$ application was carried out intraperitoneally twice per week for four weeks at $1.5 \mathrm{~mL} / \mathrm{kg}$ live weight injected together with olive oil at 1:3 ratio (Bahcecioglu et al., 2008; Shaker et al., 2010).

\section{Preparation of $N$. sativa extract}

The extract prepared by mixing the ground $N$. sativa seeds in water and boiling them was added to the drinking water of rats at a ratio of $10 \%$. The water consumption of rats was monitored and recorded regularly.

\section{Lung tissue homogenization}

Lung tissue samples were divided into small parts and were broken down inside lizis buffer (0.5 M Tris; $\mathrm{pH} 8$; EDTA, ß-mercaptoethanol, phenyl methyl sulphonyl fluoride [PMSF]) in mechanical homogenizator. These broken down tissue samples were centrifuged at 15,000 rpm for $45 \mathrm{~min}$. Supernatant was taken and stored at $80^{\circ} \mathrm{C}$ until usage time (Aslan and Can, 2014).

\section{Analysis of proteins via western blotting method}

The primary antibodies used in this study (Bio vision) were diluted at a ratio of $1 / 250$, whereas the secondary antibodies were diluted at a ratio of 1/2000 (Santa Cruz Biotechnology). Protein densities were measured using Lowry kit and $35 \mu \mathrm{g}$ protein was loaded to each well. The protein samples of the tissues were run on $12 \%$ gel via SDS-PAGE method. Afterwards, these proteins (caspase-3, caspase-9, erk, akt) were transferred to nitrocellulose membrane with western blotting method and their synthesis ratios were examined (Laemmli, 1970). The protein levels were then measured via density measurement analysis system (Image J; National Institute of Health, Bethesda, USA).

\section{Lung tissue malondialdehyde measurement}

Lung tissue samples were divided into small parts after which they were broken down in $4.5 \mathrm{~mL} 1.15 \% \mathrm{KCl}$ per $0.5 \mathrm{~g}$ tissue. Malondialdehyde determination which is the final product of lipid peroxidation was made from this prepared homogenate (Ohkawa et al., 1979; Aslan and Can, 2014; Ustundag et al., 2005). This method is based on malondialdehyde which is one of the aldehyde products of lipid peroxidation and TBA (thiobarburitic acid) reaction. $0.1 \mathrm{~mL} 8.1 \%$ sodium dodecyl sulphate (SDS), $750 \mu \mathrm{L} \mathrm{20 \%} \mathrm{(pH} \mathrm{3.5)} \mathrm{acetic} \mathrm{acid}$ solution was added to $0.1 \mathrm{~mL}$ tissue homogenate during measurement process. Afterwards, $750 \mu \mathrm{L}$ of $0.8 \%$ ( $\mathrm{pH} 3.5$ ) TBA solution was added along with distilled water to make the final volume $4 \mathrm{~mL}$. It was then left to wait in a $95^{\circ} \mathrm{C}$ boiling water bath for $45 \mathrm{~min}$ after which it was vortexed following the addition of 1 $\mathrm{mL}$ distilled water and 15:1 (v/v) ratio $5 \mathrm{~mL}$-buthanol -pyridine mixture. Following centrifugation at 5,000 rpm for $10 \mathrm{~min}$, the organic layer at the top was removed and measured spectrophotometrically at a wavelength of $532 \mathrm{~nm}$. The results were recorded as $\mathrm{nmol} / \mathrm{g}$.

\section{Statistical analyses}

All data were evaluated via SPSS 20 package software using variance analysis. One-Way ANOVA Post Hoc Tukey test was applied to determine the differences inside the groups. The measurements were repeated at least 3 times to ensure the reliability of the statistical analyses after which they were recorded in the SPSS 20 package software and evaluation process was started.

\section{Results}

\section{Live weight change and water consumption}

When the statistical data in Table I are examined, it is observed that there is a statistically significant difference among groups in terms of water consumption $(\mathrm{p}<0.05)$. Water consumption in $\mathrm{CCl}_{4}$ administered groups is lower in comparison with the control groups which show that the damage that occurs over time due to $\mathrm{CCl}_{4}$ has negative effects on water 


\begin{tabular}{|lccc|}
\hline \multicolumn{4}{|c|}{ Table I } \\
\hline \multicolumn{4}{|c|}{ Body weight and water consumption in rat } \\
\hline Groups & $\begin{array}{c}\text { First live } \\
\text { weight(g) }\end{array}$ & $\begin{array}{c}\text { Last live } \\
\text { weight }(\mathrm{g})\end{array}$ & $\begin{array}{c}\text { Daily water } \\
\text { consumption } \\
(\mathrm{mL})\end{array}$ \\
& & & 317.3 \\
Negative & 252.9 & 358.4 & $(1.5)^{\mathrm{a}}$ \\
control & $(25.1)$ & $(32.3)^{\mathrm{a}}$ & 260.4 \\
Positive & 247.9 & 309.0 & $(1.5)^{\mathrm{b}}$ \\
control & $(23.9)$ & $(20.9)^{\mathrm{b}}$ & 180.3 \\
CCl & 237.3 & 281.3 & $(1.5)^{\mathrm{c}}$ \\
& $(19.3)$ & $(15.7)^{\mathrm{c}}$ & 213.3 \\
$\mathrm{CCl}_{4}$ plus & 243.8 & 300.6 & $(1.5)^{\mathrm{d}}$ \\
$\mathrm{N}_{\text {sativa }}$ & $(18.3)$ & $(19.0)^{\mathrm{d}}$ & \\
\hline
\end{tabular}

a-d: Differences between groups in the same column with different letters are statistically significant $(p<0.05)$; Data within the parenthesis are SD; One-way ANOVA post hoc Tukey test

consumption. When the initial and final live weights of the study were compared, no statistically significant difference was determined $(p>0.05)$; whereas it is observed that there is a statistically significant difference among the final live weights $(p<0.05)$ and that the lowest live weight ratio is observed in the $\mathrm{CCl}_{4}$ group.

\section{Malondialdehyde measurement results}

When the malondialdehyde levels in the lung tissue shown in Table II are examined, no statistically significant difference is determined between the control groups $(p>0.05)$ and it was also observed that the highest malondialdehyde level is observed in the $\mathrm{CCl}_{4}$ group and that there is a statistically significant difference between other groups $(p<0.05)$. Severe decrease in the malondialdehyde levels was observed in the $\mathrm{CCl}_{4}+N$. sativa groups in comparison with the $\mathrm{CCl}_{4}$ group.

\section{Expression levels of caspase-3, caspase-9, erk, akt proteins}

The expression levels of proteins present in cell death mechanism stages are observed in the results section. When Figure 1A is examined, the caspase- 3 protein expression level differed at a statistically significant level between groups $(p<0.05)$. The highest value was observed in the negative control group and $\mathrm{CCl}_{4}+N$. sativa group, whereas the lowest value was observed in the $\mathrm{CCl}_{4}$ group. It is observed in Figure $1 \mathrm{~B}$ that the caspase-9 protein expression level shows statistically significant differences among groups $(\mathrm{p}<0.05)$. The caspase-9 protein expression level of $\mathrm{CCl}_{4}+N$. sativa group was determined to be higher in comparison with those of positive control and $\mathrm{CCl}_{4}$ groups. When the protein expression level of signal transmitting erk protein is examined in Figure 1C, no statistically significant difference was determined between the negative control and $\mathrm{CCl}_{4}+N$. sativa groups. A statistically significant difference has occurred between

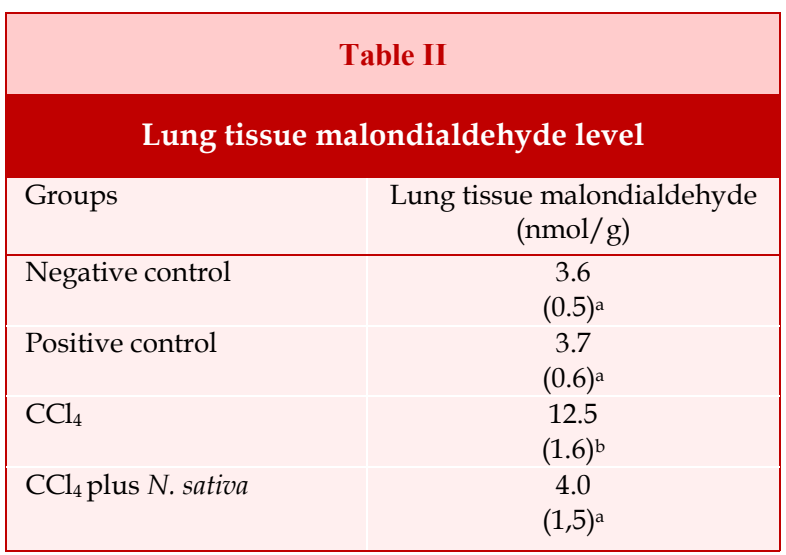

$a-b$ : Differences between groups in the same column with different letters are statistically significant $(p<0.05)$; Data within the parenthesis are SD; One-way ANOVA post hoc Tukey test

$\mathrm{CCl}_{4}$ and $\mathrm{CCl}_{4}+N$. sativa groups $(\mathrm{p}<0.05)$. The highest value was observed in the $\mathrm{CCl}_{4}$ group; whereas the lowest value was observed in the $\mathrm{CCl}_{4}+N$. sativa group. Accordingly, we can state that $N$. sativa has an effect that decreases the synthesis of these proteins. Finally, when the protein expression level of the signal transmitting protein akt is examined in Figure 1D, a statistically significant difference was observed between the groups $(\mathrm{p}<0.05)$. The akt value in the $\mathrm{CCl}_{4}$ group was determined to be greater than that of the $\mathrm{CCl}_{4}+N$. sativa group.

\section{Discussion}

The role that plants with antioxidant features play in preventing cellular and tissue damage has been clearly understood thanks to many studies carried out in recent years. Since the number of studies related with the effects of $N$. sativa on lung damage is relatively low, we are of the opinion that the results of this study will make significant contributions to literature. It was shown that $N$. sativa extract with its antitumor, bronchodilator, antidiabetic etc. effects displays antioxidant features with its free radical inhibition attribute as well as its treatment effects (Aqel and Shaheen, 1996; Harzallah et al., 2011). Ahmad et al (2013) define $N$. sativa as a miraculous plant and mention it as one that eases respiration while also having lung protective attributes thanks to its treatment effects on the trachea and respiration tract. Kanter et al (2005) examined the effects of $N$. sativa on cadmium induced oxidative stress in rat blood thus putting forth that the increase in malondialdehyde levels of plasma and erythrocytes can be decreased with $N$. sativa treatment. Sahin et al (2003) carried out a study examining the effects of $N$. sativa application on $\mathrm{CCl}_{4}$ and liver necrosis, thus putting forth that N. sativa has significant treatment effects on the malondialdehyde levels as well as various biochemical parameters such as ALT, AST. Krishnan and Muthukrishnan (2012) 


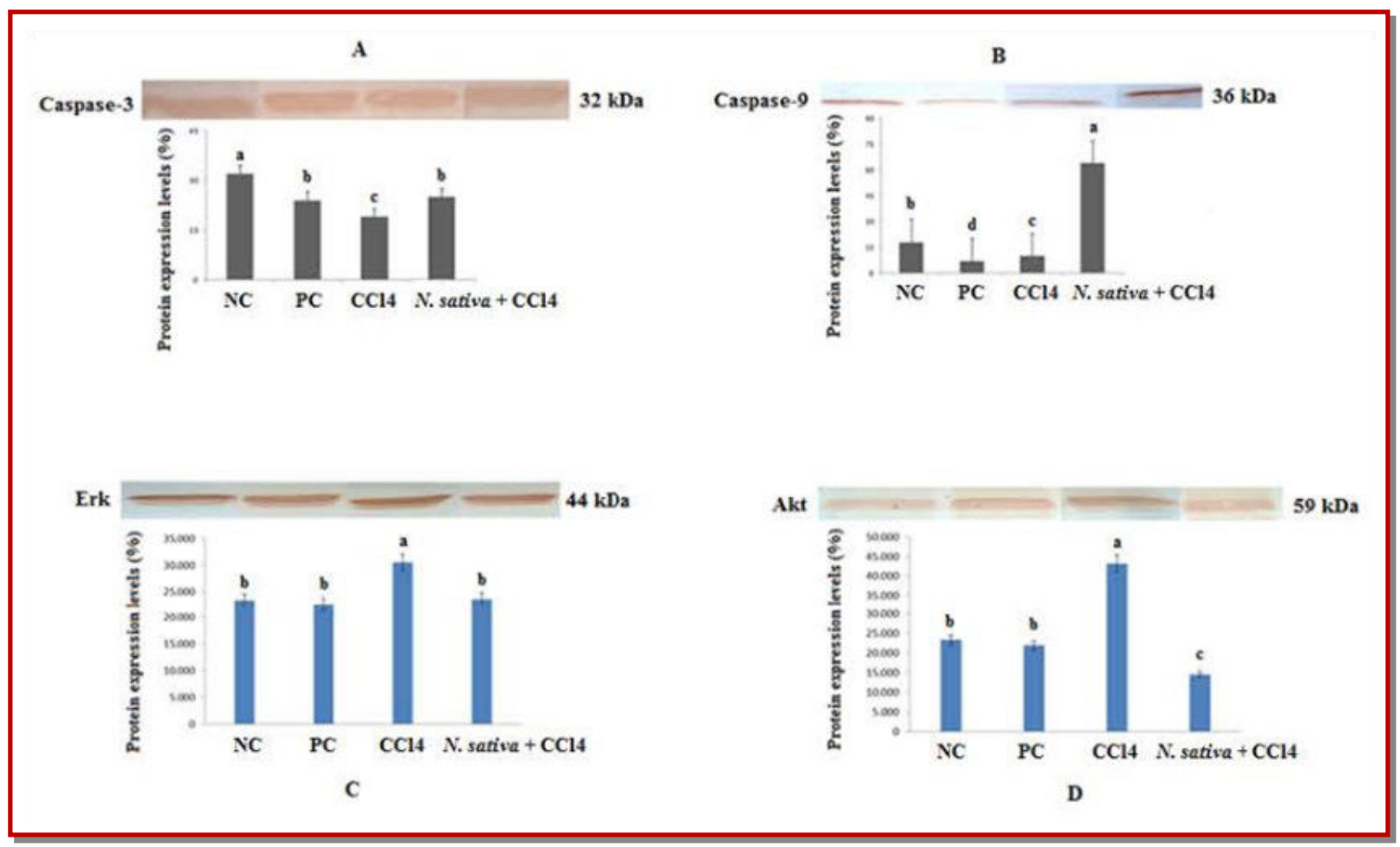

Figure 1: Caspase-3 (A), caspase-9 (B), Erk (C) and Akt (D) protein expression levels. Differences between groups in the same column with different letters are statistically significant $(\mathrm{p}<0.05)$. One-way ANOVA post hoc Tukey test.

carried out a study examining the effects of $N$. sativa seed extract on carbon tetrachloride-induced hepatotoxicity in rats thus putting forth that carbon tetrachloride causes damage on cells and tissues while disrupting many biochemical activities; while also stating that $N$. sativa seed extract administered to rats at a ratio of $10 \%$ via drinking water is quite effective on the decrease of damages on the antioxidant defense system as well as hepato-oxidative damage. Taking into account the regular rat weight determination that we conducted in our study (Table I), comparison of the first day weights and the weights 24 hours prior to slaughtering; a constant and high level of increase is observed in the control groups, whereas a lower amount of increase is observed in $\mathrm{CCl}_{4}$ administered groups. Even though the weight increase in the $\mathrm{CCl}_{4}+$ $N$. sativa group is lower in comparison with that of the control groups, a higher weight increase has been observed in comparison with the $\mathrm{CCl}_{4}$ group. In conclusion, the lowest weight increase has occurred in the rats in the $\mathrm{CCl}_{4}$ group. It can be said just by taking into consideration the differences in the increase in weight that $N$. sativa provides a protective effect on rats in comparison with $\mathrm{CCl}_{4}$ which is a strong xenobiotic and that this effect has played an important role in many factors such as the feeding of the animals. Tayman et al (2013) carried out a study examining the protective effect of $N$. sativa on the hyperoxia induced lung damage in which they divided the rats into three groups, namely, control, hyperoxia and hyperoxia $+N$. sativa thus subjecting the infant rats in the hyperoxia group to $95 \% \mathrm{O}_{2}$. Whereas they used $100 \%$ natural $N$. sativa oil in the hyperoxia $+N$. sativa group. As a result of the examination of the malondialdehyde level which is an indicator of lipid peroxidation, they reported that malondialdehyde level is much lower $(p<0.05)$ in the hyperoxia $+N$. sativa group in comparison with the hyperoxia group. When the malondialdehyde levels in the lung tissue in our results are compared (Table II), no statistically significant difference was determined between the control groups and $\mathrm{CCl}_{4}+N$. sativa group $(p>0.05)$. However, when the malondialdehyde level of the $\mathrm{CCl}_{4}$ group is examined, it is observed that it has a higher ratio in comparison with the other three groups and that there is a statistically significant difference $(\mathrm{p}<0.05)$. Based on this result, it can be stated that $N$. sativa plant is an effective antioxidant for decreasing the lipid peroxidation related malondialdehyde ratio. Jayaraman et al (2012) examined the effects of thymoquinone, a bioactive compound acquired from $N$. sativa, together with various apoptotic markers on cancer. They observed in their studies the effects of thymoquinone compound at various concentrations $(0$, $20,40 \mu \mathrm{M})$ on the expression of caspase- 3 protein in the rat neuroblastoma and have put forth that caspase- 3 expression ratio increases with increasing thymoquinone concentrations while also determining a statistically significant difference $(\mathrm{p}<0.05)$. According to our results, the caspase-3 activity in the $\mathrm{CCl}_{4}$ was lower at a statistically significant level $(p<0.05)$ in comparison 
with other groups. Whereas a statistically significant difference was not observed between the positive control and $\mathrm{CCl}_{4}+N$. sativa groups in terms of caspase3 protein expression, $(p>0.05)$ a greater caspase-3 activity was observed in the $\mathrm{CCl}_{4}+N$. sativa group in comparison with the $\mathrm{CCl}_{4}$ group (Figure $1 \mathrm{~A}$ ). In addition, caspase- 9 expression increased in the $\mathrm{CCl}_{4}+$ $N$. sativa group in comparison with the $\mathrm{CCl}_{4}$ group (Figure 1B). Hsu et al (2009) reported in their study carried out to examine the post-trauma lung damage decrease by way of ERK signal in female rats that ERK protein expression ratio is different at a statistically significant level $(\mathrm{p}<0.05)$ in all groups with trauma and especially the vehicle group thereby putting forth that ERK signal path damage triggers various cancer types. When the ERK protein expression is examined in our study; it is observed that ERK synthesis has decreased at a statistically significant level in the $\mathrm{CCl}_{4}+N$. sativa group (Figure 1C) in comparison with the $\mathrm{CCl}_{4}$ group $(\mathrm{p}<0.05)$. Khalife et al (2014) carried out a study examining the antiproliferative (preventing cell proliferation) and proapoptotic effects of the active substance of $N$. sativa on acute myelogenous leukemia and put forth as a result of the various western blot analyses of some proteins that $N$. sativa extract prevents tumor angiogenesis (formation of blood veins) and tumor growth by way of suppressing Akt and ERK activation and that it can be used as a potential drug for cancer treatment. Tuzcu et al (2012) indicated that tomato powder has positive effects on caspase activity in colon cancer. Sahin et al (2010) indicated that Epigallocatechin-3-gallate activates Nrf2/HO-1 signaling pathway in rats. Sahin et al (2012) carried out a study that chromium picolinate, phosphatidylserine, docosahexaenoic acid and boron activates the antioxidant pathway $\mathrm{Nrf} 2 / \mathrm{HO}-1$ and protects the brain against oxidative stress in high-fat-fed rats. In our study, Akt protein expression level was lower in the $\mathrm{CCl}_{4}+\mathrm{NS}$ group (Figure 1D) in comparison with the control groups at a statistically significant level. The highest expression ratio was observed in the $\mathrm{CCl}_{4}$ group and the Akt expression ratio in this group was different in comparison with those of the other groups at a statistically significant level $(\mathrm{p}<0.05)$. Thus, we think that $N$. sativa extract decreased the synthesis of these proteins by affecting the erk/akt signal path mechanism.

\section{Conclusion}

In accordance with the results we acquired, it can be stated that $N$. sativa which is a strong antioxidant plant has protective effects against the possible lung damages in rats and that similarly it can be used in humans for treating the damages in the lungs due to these therapeutic effects.

\section{Acknowledgement}

The article supported by Firat University Scientific Research Projects Unit (FUBAP) with FF.13.18 project number. Some results of this article were presented at the 3rd International Congress of Molecular Biology and Biotechnology, 2014, 02-06 June, Sarajevo.

\section{Conflict of Interest}

The authors have declared that there are no conflict of interest among the authors.

\section{References}

Ahmad A, Husain A, Mujeeb M, Khan SA, Najmi AK, Siddique NA, Damanhouri ZA, Anwar F. A review on therapeutic potential of Nigella sativa: A miracle herb. Asian Pac J Trop Biomed. 2013; 3: 337-52.

Al-Dbass AM, Al-Daihan SK, Bhat RS. Agaricus blazei murill as an efficient hepatoprotective and antioxidant agent against CCl4-induced liver injury in rats. Saudi J Biol Sci. 2012; 19: 303-09.

Aqel M, Shaheen R. Effects of the volatile oil of Nigella sativa seeds on the uterine smooth muscle of rat and guinea pig. J Ethnopharmacol. 1996; 52: 23-26.

Aslan A. The effects of different essential fruit juice and their combination on Saccharomyces cerevisiae cell growth. Progr Nutr. 2015; 17: 36-40.

Aslan A, Can MI, Boydak D, Anti-oxidant Effects of pomegranate juice on Saccharomyces cerevisiae Cell Growth. Afr J Tradit Comple-ment Altern Med. 2014; 11: 14-18.

Aslan A, Can MI. Milk thistle impedes the development of carbon tetrachloride-induced liver damage in rats through suppression of bcl-2 and regulating caspase pathway. Life Sci. 2014; 117: 13-18.

Bahcecioglu IH, Koca SS, Poyrazoglu OK, Yalnız M, Ozercan IH, Ustundag B, Sahin K, Daglı AF, Isık A. Hepatoprotective effect of infliximab, and anti-tnf-a agent, on carbon tetrachloride-induced hepatic fibrosis. Inflammation. 2008; 31: 215-21.

Harzallah H J, Kouidhi B, Flamini G, Bakhrouf A, Mahjoub T. Chemical composition, antimicrobial potential against cariogenic bacteria and cytotoxic activity of Tunisian Nigella sativa essential oil and thymoquinone. Food Chem. 2011; 129: 1469-74.

Hsu J, Kan W, Hsieh C, Choudhry MA, Bland KI, Chaudry IH. Role of extracellular signal-regulated protein kinase (erk) in $17 \mathrm{~b}$-estradiol mediated attenuation of lung injury after trauma-hemorrhage. Surgery. 2009; 145: 226-34.

Jayaraman G, Priyadharsini JV, Rajiv R, Anandan B, Raghun and Hakumar S, Shabnam J, Sambantham S, Paramasivam A. Anti-cancer effects of thymoquinone in mouse neuroblastoma (neuro-2a) cells through caspase-3 activation with down-regulation of xiap,. Toxicol Lett. 2012; 213: 151-59. 
Kanter M, Coşkun O, Gürel A. Effect of Nigella sativa on cadmium-induced oxidative stress in the blood of rats. Biol Trace Elem Res. 2005; 107: 277-87.

Khalife R, Stephany E, Tarras O, Hodroj MH, Rizk S. Anti proliferative and proapoptotic effects of topotecan in combination with thymoquinone on acute myelogenous leukemia, clinical lymphoma. Myeloma Leuk. 2014; 14: 4655.

Korsmeyer SJ. Bcl-2 gene family and the regulation of programmed cell death. Cancer Res. 1999; 59: 1693-700.

Krishnan N, Muthukrishnan S. Effect of Nigella sativa seed extract on carbon tetrachloride-induced hepatotoxicity in rats. J Acute Med. 2012; 2: 107-13.

Laemmli UK. Cleavage of structural proteins during the assembly of the head of bacteriophage T4. Nature 1970; 227: 680-85.

Li R, Chen B, Wang G, Yu B, Ren G, Ni G. Effects of mechanical strain on oxygen free radical system in bone marrow mesenchymal stem cells from children. Injury 2011; 42: 75357.

Lu Z, Xu S. ERK1/2 map kinases in cell survival and apoptosis. IUBMB Life. 2006; 58: 621-31.

Ohkawa H, Ohishi N, Yagi K. Assay for lipid peroxides in animal tissues by thiobarbituric acid reaction. Anal Biochem. 1979; 95: 351-58.

Sahin A, Yener Z, Dagoglu G, Dede S, Oto G, Alkan M The effect of Nigella sativa and vit. E + selenium in the prevention of liver necrosis experimentally induced with carbon tetrachloride (CCl4) in rats. Turk J Vet Anim Sci. 2003; 27: $141-52$.

Sahin K, Tuzcu M, Gencoglu H, Dogukan A, Timurkan M,
Sahin N, Aslan A, Kucuk O. Epigallocatechin-3-gallate activates nrf2/ho-1 signaling pathway in cisplatin-induced nephrotoxicity in rats. Life Sci. 2010; 87: 240-45.

Sahin N, Akdemir F, Orhan C, Aslan A, Agca CA, Gencoglu H, Ulas M, Tuzcu M, Viyaja J, Komorowski JR, Sahin K. A novel nutritional supplement containing chromium picolinate, phosphatidylserine, docosahexaenoic acid, and boron activates the antioxidant pathway nrf2/ho- 1 and protects the brain against oxidative stress in high-fat-fed rats. Nutr Neurosci. 2012; 15: 42-47.

Shaker E, Mahmoud H, Mnaa S. Silymarin, the antioxidant component, and Silybum marianum extracts prevent liver damage. Food Chem Toxicol. 2010; 48: 803-06.

Tayman C, Cekmez F, Kafa IM, Canpolat FE, Cetinkaya M, Tonbul A, Uysal S, Tunc T, Sarici SU. Protective effects of Nigella sativa oil in hyperoxia-induced lung injury. Archivos De Bronconeumologia. 2013; 49: 15-21.

Tuzcu M, Aslan A, Tuzcu Z, Yabas M, Bahcecioglu IH, Ozercan IH, Kucuk O, Sahin K. Tomato powder impedes the development of azoxymethane-induced colorectal cancer in rats through suppression of COX-2 expression via NF-KB and regulating Nrf2/HO-1 pathway. Mol Nutr Food Res. 2012; 56: 1477-81.

Ustundag B, Bahcecioglu I, Sahin K, Gulcu F, Duzgun S, Ozercan IH, Gursu MF. Effects of soy isoflavones on carbon tetrachloride (CCl4)-induced liver damage and on the level of plasma paraoxonase with arylesterase activities. Firat Univ Med J Health. 2005; 19: 263-71.

Vuda M, D'Souza R, Upadhya S, Kumar V, Rao N, Kumar V, Boillat C, Mungli P. Hepatoprotective and antioxidant activity of aqueous extract of Hybanthus enneaspermus against $\mathrm{CCl}_{4}$-induced liver injury in rats. Exp Toxicol Pathol. 2012; 64: 855-59. 